\section{Intraoperative awareness due to malfunction of a Siemens 900B ventilator}

Peter D. Slinger MD FRCPC,

W. Andrew C. Scott mb BS FFarcs,

A. Paul Kliffer MD FRCPC

\begin{abstract}
A case of intraoperative awareness during a thoracotomy is described. The patient's recall coincided with an intraoperative period during which a Siemens $900 B$ ventilator and a Siemens 952 isoflurane vaporiser were used. Subsequent assessment of this equipment with an anaesthetic agent analyzer revealed that, at the ventilator settings which had been used, the delivered anaesthetic vapour concentration varied greatly from the vaporizer settings. This problem eventually was traced to a malfunctioning inlet control valve on the ventilator. This complication may have been prevented if the end-tidal anaesthetic concentration had been monitored intraoperatively.
\end{abstract}

Nous décrivons un cas d'anesthesie insuffisiante non détectée, avec souvenirs des evenements perioperatoire, dúe a une valve d'entrée sur un ventilateur Siemens $900 B$ ne fonctionnant pas. Ce problème aurait pu étre éviter en monitorant la concentration d'agent volatile dans les gazs expirés.

\section{Case report}

A 71-year-old female was admitted electively for a left upper lobectomy and possible pneumonectomy. An asymptomatic mass had been discovered in the left lung on a routine chest radiograph. The patient had a 25 pack-year smoking history and was a non-insulin dependant diabetic controlled on oral chlorpropamide $250 \mathrm{mg}$ per day for the previous five years. The patient described mild orthostatic dizziness and occasional palpitations associated with anxiety. She denied any other cardiorespiratory symptoms. The patient had had two previous general anaesthetics for gynaecological surgery without complications. There was no history of drug or alcohol abuse.

\section{Key words}

ANAESTHESIA: depth, awareness:

COMPLICATIONS: awareness; EQUIPMENT: ventilators, malfunction.

From the Departments of Anaesthesia of the Montreal General Hospital and McGill University.

Address correspondence to: Dr. P. Slinger, Room 840, Montreal General Hospital, 1650 Cedar Avenue, Montrcal, Quebec, Canada H3G IA4.
The patient's height was $1.53 \mathrm{~m}$ and her weight $45 \mathrm{~kg}$. There were no abnormalities on physical examination. Preoperative ECG revealed sinus rhythm at $75 \mathrm{~min}^{-1}$ with non-specific ST-segment changes and occasional unifocal premature ventricular contractions (PVC's). Chest $x$-ray showed a $3 \mathrm{~cm}$ diameter mass in the left mid-lung field. Spirometry, arterial blood gas analysis, haemoglobin, urinalysis and liver enzymes were all within mormal limits.

The patient was premedicated with promethazine $25 \mathrm{mg}$ and glycopyrrolate $0.2 \mathrm{mg} \mathrm{IM}$ one hour preoperatively. On arrival in the operating room the heart rate was 110 $\min ^{-1}$, blood pressure $125 / 75 \mathrm{mmHg}$ and the ECG revealed unifocal PVC's at a rate of $10 \mathrm{~min}^{-1}$. An IV line was placed and diazepam $5 \mathrm{mg}$ and fentanyl $100 \mu \mathrm{g}$ administered. Subsequently, a radial artery line was placed and general anaesthesia induced with fentanyl 100 $\mu \mathrm{g}$, thiopentone $225 \mathrm{mg}$ and the lungs were ventilated with isoflurane two per cent in oxygen. After pancuronium $5 \mathrm{mg}$ and lidocaine $60 \mathrm{mg}$, a \#35Fr right doublelumen bronchial tube was placed. Following intubation the heart rate was $100 \mathrm{~min}^{-1}$, blood pressure $108 / 64$ $\mathrm{mmHg}$ and there were no PVC's. A further $3.5 \mathrm{mg}$ pancuronium was admimistered incrementally during the four-hour anaesthetic to maintain $>95$ per cent thumb twitch depression and anaesthesia was maintained with isoflurane in oxygen.

After induction of anaesthesia the patient was placed in the right lateral decubitus position and the position of the bronchial tube was verified by bronchoscopy. Prior to skin incision one further dose of fentanyl $50 \mu \mathrm{g}$ was given. Heart rate decreased to $80 \mathrm{~min}^{-1}$ and blood pressure decreased to $90 / 45 \mathrm{mmHg}$ after thoracotomy which required a brief infusion of phenylephrine $40 \mu \mathrm{g}$ $\mathrm{ml}^{-1}$. During the anaesthetic the heart rate remained between 80-96 $\mathrm{min}^{-1}$ without PVC's and the systolic blood pressure remained between $90-140 \mathrm{mmHg}$. The oxygen saturation during both two-lung and one-lung ventilation remained $>97$ per cent as determined by pulse oximetry and intermittant arterial blood gas analyses.

From the time of induction until the initiation of one-lung ventilation (105 min) a Penlon AM 1000 anaesthetic machine was used in combination with a Penlon PPV isoflurane vaporizer and a Nuffield 400 
TABLE I Per cent concentration of delivered isoflurane vapour at different tidal volume settings *

\begin{tabular}{llll}
\hline & \multicolumn{3}{l}{ Inspired concentration setting (\%) } \\
\cline { 2 - 4 } Tidal vol $(\mathrm{ml})$ & 1 & 2 & 3 \\
\hline 500 & 0.2 & 0.5 & 1.3 \\
600 & 0.35 & 0.85 & 1.6 \\
800 & 0.55 & 1.45 & 2.45 \\
\hline
\end{tabular}

*Respiratory rate $=10 \mathrm{~min}^{-1}$, inspiratory time $=33$ per cent, for all tidal volumes.

ventilator (Penlon, Abingdon, England). The inspired concentration set on the isoflurane vaporizer was varied between $0.75-2.0$ per cent to keep the systolic blood pressure within 20 per cent of the pre-induction value.

During the period of one-lung ventilation $(70 \mathrm{~min})$ a Siemens 900 B ventilator with a Siemens 952 isoflurane vaporizer (Siemens-Elema, Sweden) was used to monitor the expired minute volume. The dialed inspired isoflurane concentrations varied between $1.0-1.5$ per cent. From the resumption of two-lung ventilation to the end of the case (65 $\mathrm{min})$, the Penlon anaesthetic machine, vaporizer and ventilator were re-employed. A tidal volume of $500 \mathrm{ml}$, respiratory rate of $10 \mathrm{~min}^{-1}$ and inspiratory:expiratory ratio of 1:2 were used for both two- and one-lung ventilation. The patient underwent an uncomplicated left upper lobectomy.

At the conclusion of surgery a lumbar epidural catheter was placed and the residual muscle relaxation was reversed with neostigmine $2.5 \mathrm{mg}$ and glycopyrrolate 0.6 mg. After ventilation with oxygen, the trachea was extubated when the patient was awake and she was transported to the recovery room.

On admission to the recovery room the patient complained that she had been awake during part of the operation. On subsequent questioning by several physicians, over the next five days, her description of the experience did not change. She remembered lying on her right side, being unable to move and having a "terrible pain" in her left chest. She did not remember hearing voices. She did not remember intubation, positioning or awakening in the operating room at the end of the anaesthetic. Her first consistent postoperative memories began in the recovery room. The patient was extremely distressed by her memories and by the initial lack of an explanation.

A recheck of the anaesthetic apparatus showed both vaporizers still contained anaesthetic agent and the ventilators both delivered appropriate tidal volumes. There were no problems with the pipeline oxygen supply. Both anaesthetic machines were subsequently assessed for the accuracy of the delivered anaesthetic vapour
TABLE II Per cent delivered isoflurane vapour at different ventilator inspiratory time settings

\begin{tabular}{llll}
\hline $\begin{array}{l}\text { Inspiratory } \\
\text { time } \\
(\%)^{*}\end{array}$ & $\begin{array}{l}\text { Set inspiratory } \\
\text { concentration } \\
(\%)\end{array}$ & $\begin{array}{l}\text { Delivered } \\
\text { inspiratory } \\
\text { concentration } \\
(\%) \dagger\end{array}$ & $\begin{array}{l}\text { Delivered } \\
\text { inspiratory } \\
\text { concentration } \\
(\%) \mp\end{array}$ \\
\hline 15 & 1 & 1.1 & 0.85 \\
20 & 1 & 0.8 & 0.85 \\
25 & 1 & 0.5 & 0.85 \\
33 & 1 & 0.2 & 0.85 \\
50 & 1 & 0.1 & 0.85 \\
\hline *Tidal volume & $=500 \mathrm{ml}$ respiratory rate $=10 \mathrm{~min}^{-1}$ & pausc $=0$ per
\end{tabular}

*Tidal volume $=500 \mathrm{ml}$, respiratory rate $=10 \mathrm{~min}^{-1}$, pausc $=0 \mathrm{per}$ cent.

tDelivered concentration before replacement of ventilator inlec control valve.

$¥$ Delivered concentration after replacement of ventilator inlet control valve.

concentration using a Puritan-Bennett model \#222 Anaesthetic Agent Analyzer (Datex, Finland). The output from the Penlon isoflurane vaporizer measured at the fresh gas outlet of the anaesthetic machine was \pm 10 per cent of the dialed concentration over a wide range of fresh gas flows. However, the vapour concentration measured at the inspiratory outlet of the Siemens ventilator varied greatly from the dialed inspiratory concentration set on the vaporizer. The magnitude of this error varied directly with the duration of inspiration ( $\mathrm{Ti}$ ) and inversely with the minute ventilation (see Tables I, II, and III).

Subsequently, the Siemens isoflurane vaporizer was replaced with a new Siemens 952 isoflurane vaporizer but the output vapour concentration showed the same pattern and degree of error as with the initial Siemens vaporizer. After replacement of the control inlet valve of the gas supply unit on the Siemens ventilator the isoflurane vapour output was within \pm 15 per cent of the set desired inspired concentration (Table II and III).

TABLE III Per cent delivered isoflurane vapour at different ventilator respiratory rate settings

\begin{tabular}{llll}
\hline $\begin{array}{l}\text { Respiratory } \\
\text { rate* (cycles } \\
\left.\min ^{-1}\right)\end{array}$ & $\begin{array}{l}\text { Set inspiratory } \\
\text { concentration } \\
(\%)\end{array}$ & $\begin{array}{l}\text { Delivered } \\
\text { inspiratory } \\
\text { concentration } \\
(\%) \dagger\end{array}$ & $\begin{array}{l}\text { Delivered } \\
\text { inspiratory } \\
\text { concentration } \\
(\%) \ddagger\end{array}$ \\
\hline 10 & 1 & 0.2 & 0.85 \\
15 & 1 & 0.6 & 0.85 \\
20 & 1 & 1.1 & 0.85 \\
30 & 1 & 1.4 & 0.85 \\
\hline
\end{tabular}

*Inspiratory time $=33$ per cent, pause $=0$ per cent, tidal volume $=$ $500 \mathrm{ml}$.

†Delivered concentrations measured before replacement of ventilator inlet control valve.

$¥$ Delivered concentrations measured after replacement of ventilator inlet control valve. 


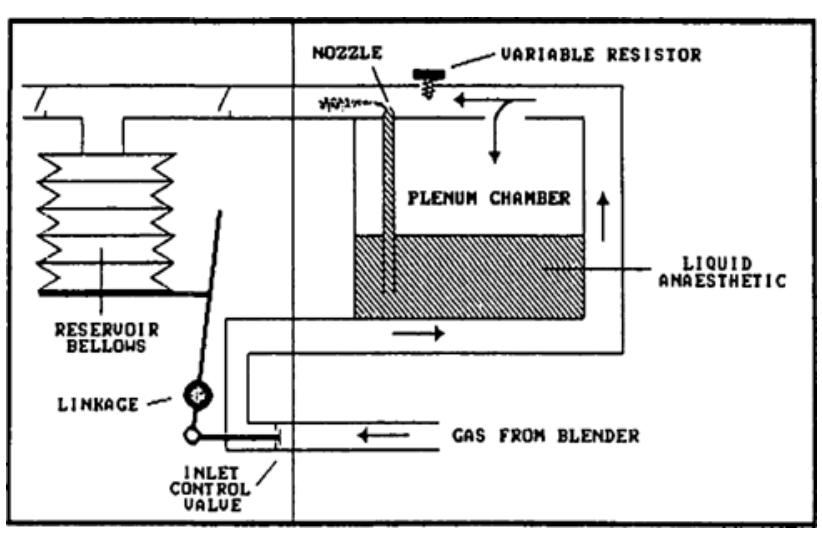

FIGURE Schematic representation of high pressure gas system on a Siemens 900 B ventilator with 950 series vaporizer attached. A vertical line separates components in the ventilator (on left) from those that are part of the vaporizer.

The patient was greatly relieved to be offered a rational explanation for her intraoperative awareness and an assurance that this error could be avoided during future general anaesthetics.

\section{Discussion}

The precise cause of the vaporizer malfunction remains unclear to the authors; the following hypothesis fits the known facts. Because gas flows intermittently at high pressure from the gas blender to the intemal reservoir bellows in the Siemens 900 series ventilators a continuous flow (Tec type) vaporizer may not be used. The Siemens 950 series vaporizers use the plenum principle which is similar to that of a gasoline carburetor to add vapour to the inspired gas (Figure).

The carrier gas flow passes through a variable restriction which increases the pressure inside the plenum chamber and forces liquid anaesthetic to be ejected through the nozzle into the gas stream. The restriction can be adjusted in order to alter the inhaled concentration using a scaled knob. In order to function correctly the flow through the vaporizer must be constant and independent of the ventilator settings. The inlet control valve in the ventilator opens when the reservoir bellows volume becomes decreased and closes when it is replenished. In the case of the malfunction which developed in this particular ventilator, settings which resulted in a low inspiratory flow (i.e., low tidal volume or long $T_{1}$ ) apparently resulted in a reduced opening of the inlet control valve. As a result the fresh gas flow was too small to generate an adequate pressure in the plenum chamber and the resulting vapour concentration was lower than indicated by the scale.

During the period of one-lung ventilation we estimate that the inspired isoflurane concentration decreased to 0.2 per cent $\mathrm{v} / \mathrm{v}$. This concentration of isoflurane is very close to the "MAC-awake" of isoflurane ( 0.19 per cent $){ }^{2}$ The patient's description is consistent with awakening in mid-operation and seems to coincide with the period of use of the Siemens ventilator. Her lack of recall of voices could be related to some residual anaesthetic effect or to the subdued atmosphere in the operating room. Previously reported cases have described intraoperative awareness without haemodynamic abnormalities or recall of voices. ${ }^{3}$ In this case some degree of diabetic autonomic neuropathy may have contributed to the lack of haemodynamic changes.

The Siemens vaporizer/ventilator combination described had been used for at least 20 previous anaesthetics, during many of which an end-tidal anaesthetic vapour analyzer had been employed and no problem encountered. All these patients had been visited postoperatively, yet none complained of inadequate anaesthesia. However, the ventilator had not previously been used at such a low minute volume setting and our subsequent investigation revealed the effects of the malfunction became magnified at lower minute volumes.

The Siemens ventilator was preferred during one-lung ventilation because it continuously measures expired volume. A right double-lumen tube was inserted because there was a possibility of a left pneumonectomy. Since right-sided endobronchial tubes have a greater tendency to leak around the bronchial cuff during one-lung ventilation than left-sided tubes, measuring the expired volume is helpful in the assessment of the adequacy of ventilation.

Intraoperative awareness is a recognized complication of narcotic/relaxant anaesthetic techniques ${ }^{3}$ and during anaesthesia for caesarean section ${ }^{4}$ or major trauma with haemodynamic instability. Awareness is less common during anaesthesia with halogenated volatile anaesthetics since these arugs tend to abolish awareness at a lower concentration than that at which they abolish autonomic reflexes. However, awareness can occur during any type of surgery with any anaesthetic technique if there is an equipment malfunction. Intraoperative awareness is extremely distressing to the patient who may benefit from a rational explanation of why it occurred and sympathetic reassurance that the memories are real. The anaesthetist must believe the patient and exhaust every possibility to find the cause.

The incidence of accidental intraoperative awareness may be increasing. ${ }^{5}$ Unfortunately, neither clinical signs nor monitors, including the $\mathrm{EEG},{ }^{6}$ can reliably determine whether the patient is aware or not. As anaesthetic equipment becomes more complex, the anaesthetist must be even more thorough in testing the apparatus throughout all ranges of clinical function. 
During intra-thoracic procedures, muscle relaxation facilitates surgery without the haemodynamic complications of deep inhalational anaesthesia. Whenever profound muscle relaxation is used there is a risk of intraoperative awareness. The addition of an anaesthetic vapour analyzer to the monitoring of this patient may have prevented this complication.

In summary, a case is presented of intraoperative awareness during a thoracotomy that was traced to a malfunctioning inlet control valve of a Siemens 900B ventilator. Anaesthetists using similar equipment should verify the anaesthetic vapour delivery over a wide range of minute ventilation and inspiratory time settings.

\section{Acknowledgments}

The authors would like to thank Miss C. Colligan for her secretarial assistance and Dr. D. Whalley for his advice and review of the manuscript.

\section{References}

1 Siemens Isoflurane vaporizer 952 operating manual: 5 th ed, Siemens-Elena AB (Solna, Sweden) 1985: 4.

2 Gross $J B$, Alexander CM. Awakening concentrations of isoflurane are not affected by analgesic doses of morphine. Ancsth Analg 1988; 67: 27-30.

3 Guerra $F$. Awareness and recall. Int Anesthesiol Clin 1986; 24(4): 75-99.

4 Schultetus RR, Hill CR, Dharamraj CM, Banner TE, Berman $L S$. Wakefulness during Cesarean section after anesthetic induction with ketamine, thiopental or ketamine and thiopental combined. Anesth Analg 1986; 65: 723-8.

5 Aldrete JA. Is the patient asleep? Int Surg 1987; 72: 58-61. 6 Mori $K$. The EEG and awareness during anaesthesia. Anaesthesia 1987; 42: 1153-5. 